\title{
Factors Influencing Swift and Effective Resolution of Supplier Problems
}

\begin{abstract}
Purpose - How might an organization swiftly resolve supplier problems such that the issue does not reoccur? This study seeks to understand the impact of different knowledge-sharing routines on measures of effective problem resolution.
\end{abstract}

Design/methodology/approach -Data is collected from an automotive manufacturer's (buyer) database. A hierarchical linear model analyzes dyadic data collected from 155 problems across 24 suppliers.

Findings - This study reveals that different ways of communicating have differing impact on measures of effective problem solving. Communication involving face-to-face interaction slows the process. Whereas, frequent communication can lead to swift resolution. Furthermore, management teams are more likely to lead to a "better" fix in that these teams are more likely to implement changes in the process or product.

Research limitations/implications - The data is for a tier-one automotive supplier. Hence, the findings are limited by the extent to which other organizations may differ.

Practical implications -The results provide insights for managers experiencing supply issues. Some forms of communication should be encouraged as they enhance the process. Moreover, the findings suggest there are consequences to pressuring a supplier to resolve a complaint quickly.

Originality/value - Very few researchers can claim to have investigated observed collaborative mechanisms that occur between a buyer and its suppliers when resolving a problem. This research adds to the literature on the relational view theory as it applies to supply chain management and problem resolution. 
Keywords: Quality, Supplier Quality Management, Problem Solving, Communication

\section{Introduction}

In today's global economy, supply chains are known to play a significant role in a firm's performance. Managing these supply chains requires an inter-firm collaborative approach. Chen and Paulraj (2004) suggest that the dyadic and collaborative partnerships existing in supply chains impact supply chain performance. The authors extend the relational view, developed by Dyer and Singh (1998) to supply chains. Dyer and Singh suggest that organizations compete through collaborative partnerships because of the presence of critical resources existing in interfirm relationships. Adopting these collaborative practices within a supply chain impacts both operational and strategical aspects of performance (Kuei et al., 2008). These practices are particularly important when supply issues occur.

The recall of Samsung's Note 7 highlights the importance of achieving swift resolution for a supplier quality issue. Samsung initially determined that the problem of exploding batteries was related to one supplier (Cheng and Jeong, 2016). However, the corrective action undertaken was ineffective and when the problem persisted across multiple suppliers, Samsung had to dig deeper to determine the root cause and reach an irreversible corrective action. This ineffective and time-consuming resolution led to a product recall at a cost of $\$ 5.3$ billion (Lopez, 2017). The Samsung example highlights the significance of problem resolution in buyer-supplier relationships in that supplier performance and development are integrally tied to both the buyer's performance and the supplier's performance (Carr and Kaynak, 2007; Park et al., 2006).

The relational view of the firm as it applies to supply chains (Dyer and Singh, 1998; Chen and Paulraj, 2004) recognizes knowledge sharing routines as one source of value in buyersupplier relationships. These routines encompass mechanisms for communicating and sharing 
information which in turn build collaborative relationships. These relational mechanisms are dyadic in nature and exist within supply chains. Previous research demonstrates that relationship mechanisms are critical to supply chain performance (Paulraj et al., 2008). Despite the research that indicates the importance of communication mechanisms for supply chain success, it is surprisingly one of the biggest areas in need of improvement (Oxford College of Procurement and Supply, 2019). What is not clear is whether all mechanisms have the same effect. Recent quality problems in the automotive industry highlight the important role of collaboration in manufacturing supply chains. A recall by Toyota involving 5.8 million vehicles with faulty air bags was mishandled due to poor communication between the supplier and Toyota (McLain, 2016).

Few studies explore how different mechanisms of communicating and sharing information differ in their impact on specific performance measures of problem resolution. These mechanisms build relationships and this research finds that these mechanisms have mixed results, some positive, some negative, and some insignificant. The remainder of this paper includes a background section discussing the relational view as it applies to supply chains, supply chain quality management, and problem resolution. This is followed by the research model, method of analysis, results, discussion, implications, and suggestions for future research.

\section{Background}

\subsection{The Relational View in Supply Chain Management}

The supply chain management literature utilizes the relational view as a foundational concept (Chen and Paulraj, 2004). Supply chains can be viewed as a network of relationships that provide material, information, and services. The literature on supply chain management discusses the competitive advantages for a supply chain resulting from an investment in the buyer-supplier 
relationship. Firms may realize an advantage by focusing on this buyer-supplier network and establishing inter-organizational routines and processes (Lascelles \& Dale, 1989; Krause 1998; Paulraj et al., 2008; Wagner and Krause, 2009). Business strategies based on the relational view promote the development of a complex network of buyers and suppliers with long-term as well as dependent relationships between firms. Focusing on these collaborative partnerships, the relational view of the firm (Dyer and Singh, 1998) suggests that relational rents provide the primary source of competitive advantage for a firm. Dyer and Singh (1998) propose that a firm's critical resources extend beyond the firm's boundaries existing in inter-firm resources and routines. They argue that there are four sources that provide a competitive advantage; 1) relation specific assets, 2) knowledge-sharing routines, 3) complementary resources or capabilities, and 4) effective governance. The relational view is particularly relevant in supply chains where the relational linkages between buyer and supplier create value.

This study explores one aspect of the relational view, knowledge-sharing routines. This study builds on previous work which discusses the positive benefits of inter-firm knowledge sharing routines. Ko et al. (2005) examine knowledge transfer from consultants to clients to find that communication-related mechanisms are one of the factors to influence knowledge transfer. Focusing on strategic information flows, Klein and Rai (2009) find that buyer and supplier information flow positively impacts the performance of both parties. Li et al. (2012) find that collaborative knowledge management practices improve the quality of knowledge shared between firms. Dyer and Nobeoka (2000) observe that Toyota and its suppliers are productive and solve problems effectively because of their inter-firm knowledge sharing routines that facilitate the sharing of valuable knowledge. Charterina and Landeta (2013) find buyer-supplier 
relationships that encourage an exchange of knowledge have a positive impact on the firm's innovativeness, thus reinforcing the positive influence of knowledge-sharing efforts.

\subsection{Quality Management in Supply Chains}

Supplier management is undoubtedly a critical component of quality management. The early work of Deming (1986) recognizes that a firm must be involved in supplier improvement efforts in order to manage quality, resulting in continuous improvement of incoming quality. Historically, quality improvement practices were implemented at a manufacturer's location. Extending these efforts to a firm's supply chain can have a positive effect on both quality and the supply chain performance. When supply chain management focuses on relational mechanisms that integrate practices and processes, supply chain performance improves (Robinson and Malhotra, 2005). This systematic approach is identified in the literature as Supply Chain Quality Management (SCQM), where Foster (2008) defines SCQM as "a systems-based approach to performance improvement that leverages opportunities created by upstream and downstream linkages with suppliers and customers". SCQM includes practices such as supplier focus, process control, and supply chain integration that positively impact product quality (Antony, 2015; Soares et al., 2017). These collaborative practices require a commitment of resources, personnel, communication, and increased involvement in the supplier's processes (Krause et al., 1998). Furthermore, it has been shown that poor communication and unstructured supplier improvement programs hinder quality performance (Lascelles and Dale, 1989). Support for the positive benefits of inter-organizational collaboration and communication is provided by Paulraj et al. (2008) and Gligor and Holcomb (2012). Applying these practices at the operational level will have a positive effect on supply chain performance of a firm (Kuei et al., 2008). 


\subsection{Problem Resolution in Supply Chains}

Supply chains are repeatedly confronted with problems that disrupt production and impact quality. These supply issues are often discovered by the buyer, but the supplier has the knowledge and resources to solve these problems. Problem resolution in these situations requires coordination and communication between the buyer and supplier, especially for problems that create a significant disruption to production or quality. Zhang et al. (2011) find that collaboration within a supply chain leads to continuous improvement. Suppliers who are capable of problem solving through collaboration and coordination are successful partners for firms (Wood et al., 1996). Therefore, it is important during supplier development activities to build problem-solving skills which improve a supplier's technical capabilities and are especially critical when dealing with problems that have a significant impact on the buyer's production or quality performance (Liker and Choi, 2004).

Problem solving requires a substantial exchange of information between organizations. When conflicts occur, effective buyer-supplier relationships result in improved problem resolution. Effective relationship mechanisms include information sharing which facilitates understanding between supply chain partners (Pooe et al., 2015). Sharing timely, accurate, and relevant information becomes critical. Therefore, it is important to establish relationship mechanisms as a norm in the buyer-supplier relationship (Bello and Bovell, 2012). Furthermore, small groups can facilitate communication and information exchange which is found to be an effective quality management practice (Phan et al., 2011). When these small groups work as a team, they can have a direct and positive affect on operational performance (Salaheldin, 2009). General Motors utilizes technical problem-solving teams to improve efficiency wherein the 
teams implement permanent corrective actions to resolve vehicle performance issues (Schmidt, 2012).

The key premise of this paper is that problem resolution performance improvements can be achieved through value-adding processes that enable inter-firm information sharing which builds collaborative partnerships, thus providing a competitive advantage. This paper examines relational mechanisms that occur between a buyer and a supplier because of their role in problem resolution. Specifically, the study asks a) what communication practices lead to swift resolution of supplier problems, and b) how do these practices influence the effectiveness of the supplier's corrective action.

\section{Research Model}

The objective of this study is to explore how knowledge sharing mechanisms impact two aspects of problem resolution. The first measure considers how quickly a problem is resolved. When there is a significant problem disrupting production or creating quality issues, buyer and supplier are motivated to resolve the issue quickly and effectively. Bourgeois and Eisenhardt (1988) finds that successful firms make decisions carefully and take action quickly. Moreover, a good supplier not only resolves problems quickly, but does it in such a manner that the problem does not reoccur (Sims, 2011). Thomas et al. (2011) study buyer-supplier relationships under the pressure of time. The authors find that time pressure coping mechanisms can result in a negative impact on the quality of communication and decisions. Zander and Kogut (1995) note that correct means of communication leads to a faster knowledge transfer. Therefore, the objective of this study is to explore means of communicating and their impact on time. Problem resolution time is defined by the time span that begins on the date when the problem is reported and ends on 
the date the buyer is assured the supplier successfully eliminated the potential for future occurrences and considers the problem resolved.

The problem resolution may also result in different types of actions. A solution to the problem (corrective action) may involve a change in how the supplier manufactures the product or a product redesign and is referred to as a technology corrective action. A change in technology may require purchasing or refurbishing equipment, changing product or process prints and securing customer approval, which takes time. Technology changes do not require a person to do something different; rather, the process or product is altered and therefore a reversal to past practice is less likely. The most effective corrective actions involve a change in technology as opposed to a change in operator practices (Argote, 2012; Agrawal and Muthulingam, 2015). If the corrective action involves training or changing an operator procedure it is classified as an operator corrective action. Narayanan et al. (2009) show that individuals are unreliable for knowledge retention and changes in operator practices can be reversed. Agrawal and Muthulingam (2015) find that knowledge depreciation is less when knowledge is embedded in process or product changes. This suggests that a technology change may be more desirable. Therefore, the type of corrective action implemented is considered.

Given that problem-solving is enhanced when both parties communicate and share critical information, this analysis seeks to understand how these different relationship building mechanisms impact the time and actions taken to resolve a supplier problem. It is hypothesized that different practices have differential impacts on problem resolution time and the corrective action implemented. 


\subsection{Dense Communication}

Buyers and suppliers communicate during the design, planning, and production phase of operations, as well as during problem resolution. Communicating frequently enhances the relationship between the buyer and supplier and leads to improved operational performance for both the buyer and supplier. Effective inter-organizational communication is characterized as frequent, genuine, and involves personal contact between buyer and supplier which has a positive impact on supply chain performance (Chen and Paulraj, 2004). Frequent communication between a buyer and a supplier and its content are significant factors that lead to supplier performance improvements (Modi and Mabert, 2007). This frequent exchange of information especially impacts supplier performance with respect to product quality and reliability of delivery (Large, 2005). With regard to problem-solving, MacDuffie (1997) finds an increase in communication leads to a richer exchange of information. This is particularly critical when the problem involves technical information or specifications. Carr and Kaynak (2007) show that frequent and timely information sharing between firms contributes to a buyer's performance improvement through supplier development. Time related performance measures particularly improve when suppliers interact with buyers on issues through improvements or actions (Salvador et al., 2001). The supplier issues studied in this research cause significant disruptions to production or quality, resulting from a failure to meet product specifications or delivery requirements. Therefore, it seems reasonable that an increase in communication results in a better understanding of the problem from both the buyer's and the supplier's perspective. Discussing the problem, both symptoms and impact, helps the supplier to better define the problem and understand the needs of the buyer, which in turn leads to a corrective action that better aligns with the buyer's process. This analysis considers how often the buyer and supplier 
communicate over a given period of time. It would seem logical that the longer a complaint remains open, the more communication occurs. Therefore, the number of communications per time unit is measured. This measure is a ratio called dense communication. The number of communications is determined by the number of documented communications between the buyer and supplier, as noted in the database. Hypotheses 1 proposes that dense communication speeds the process of problem resolution and impacts type of corrective action implemented.

H1a: Dense communication is negatively associated with problem resolution time.

H1b: Dense communication is positively associated with technology corrective actions.

\subsection{Employee Communication}

Employee involvement is an important practice for any quality management initiative (Bajaj et al., 2018). Not only do employees have first-hand experience and knowledge of the process, but often they are directly impacted by any procedural, process or product changes. Thus, it is important to consider problems from the viewpoint of the employees and to gain their insights. Because face-to-face communication allows a rich sharing of information it may motivate employees to be involved and committed to resolving customer complaints. These rich channels of communication, involving face-to-face interaction also reduce communication error (Wagner and Krause, 2009). Employees can provide valuable information and are empowered when involved in quality improvement efforts (Habtoor, 2016). When employees feel free to express issues in meetings with management and discuss best ways to solve problems, productivity issues are resolved (Jagoda, 2013). Therefore, hypotheses 2 proposes that the time to resolve issues will be reduced and a more effective corrective action will be reached.

H2a: Employee meetings are negatively associated with problem resolution time. $\mathrm{H} 2 \mathrm{~b}$ : Employee meetings are positively associated with technology corrective actions. 


\subsection{Onsite Visits}

Onsite visits are a form of face-to-face communication which require a level of trust and transparency. These visits can be the buyer visiting the supplier's facility and/or the supplier touring the buyer's facility. During these visits, buyer and supplier share significant information about their processes or product. Such visits provide an opportunity to share tacit information about operational processes, which enhances the buyer's competitive position or improves supplier performance (Modi and Mabert, 2007). Supplier performance improvements may result in reduced cost, improved quality, or improved delivery performance which directly impacts the buyer's performance. Outside the problem-solving process, buyers may visit supplier facilities in order to conduct supplier audits, provide training to suppliers that can positively affect suppliers' knowledge and capabilities, and in turn the buyer's performance. MacDuffie (1997) provides an example where operational knowledge is shared between Honda and its suppliers, resulting in improved supplier performance. Wagner and Krause (2009) show face-to-face human interaction improves suppliers' capabilities. As buyer-supplier relationships become collaborative in nature, buyers are more apt to visit supplier firms as part of the problem-solving process. For instance, Toyota routinely sends teams of employees to visit suppliers, particularly to solve quality problems (Dyer and Nobeoka, 2000). Scheduling onsite visits takes time due to the logistics of travel and coordinating individual schedules, but this method of collaboration may lead to a more effective corrective action which offsets the potential increase in problem resolution time. Hypotheses 3 proposes:

H3a: Onsite visits are positively associated with problem resolution time.

H3b: Onsite visits are positively associated with technology corrective actions. 


\subsection{Management Teams}

Effective problem solvers are creative and provide novel solutions to problems. Groups of people working together can arrive at solutions that are creative and depart significantly from what might arise otherwise (Harvey, 2014). An early study by Brown and Duguid (1991) suggest that innovation and learning take place in informal groups and these communities-of-practice should be encouraged. Toyota solves emerging problems by forming problem solving teams that collectively bring their knowledge together to "fix" the problem (Dyer and Nobeoka, 2000). For a given supplier, these groups may already be established and are referred to as management teams. The teams often are cross-functional, consisting of individuals from operations, engineering, quality, logistics, or purchasing. Utilizing these teams for problem solving is identified as one of the best practices in the supply chain quality management framework developed and validated by Robinson and Malhotra (2005). The advantage of teams is that different perspectives are represented when individuals are brought together from other disciplines (MacDuffie, 1997). Additionally, teams are an important means of collaborating when looking to improve quality. Given that cross-functional management teams may already be established, the supplier can quickly collaborate with these teams to review and discuss a customer complaint. Moreover, the teams might have the necessary resources to implement a more effective solution. Hypotheses 4 proposes management teams will arrive at a better solution to the complaint and do this quickly.

H4a: Management teams are negatively associated with problem resolution time.

H4b: Management teams are positively associated with technology corrective actions. 


\subsection{Sharing Information}

One aspect of communication occurs when the supplier shares relevant documents in the database. Swink (2006) finds that information sharing promotes collaboration. Toyota's successful knowledge sharing network includes the sharing of information (Dyer and Nobeoka, 2000). Wagner and Krause (2009) find problem resolution is enhanced when information is shared between buyer and supplier. Another advantage of information sharing is reduced conflict between buyer and supplier, which in turn enhances understanding, and improves supplier performance (Pooe et al., 2015). For this study, documents are uploaded into the database and may include data verifying the effectiveness of the corrective action, product or process documentation, operator procedures, root cause analysis documents, information on delivery, activity logs, etc. These documents contain valuable information, which is reviewed by the buyer. The buyer in turn may request more information or clarification. However, there is a consequence to sharing information, it takes time to process. Thomas et al. (2011) reveal that when suppliers are pressed for time it decreases the exchange of information between the buyer and supplier. Each document provided by the supplier is reviewed by the buyer. Therefore, it is reasonable to expect that the review time increases as the number of documents increase. Also, a technology corrective action may require additional supporting documentation. In hypotheses 5, it is proposed that:

H5a: The number of documents shared is positively associated with problem resolution time.

H5b: The number of documents shared is positively associated with technology corrective actions. 


\subsection{Sharing Sensitive Information}

One dimension of information sharing is the sharing of sensitive information, which includes proprietary documents, such as process or product prints and failure mode and effect analysis (MacDuffie, 1997). These documents contain rich information about the supplier's operations, which includes process specifications and build specifications for the supplier's product. Failure mode and effect analysis is a thorough analysis of what might go wrong with either the product or process and reveals the control systems established by the supplier to prevent failures. Sharing documents such as these, which are rich in information, displays a level of trust and collaboration between the buyer and supplier. Moreover, the literature reveals measures for success include sharing strategic information which results in improved supplier performance and quality (Pooe et al., 2015; Ragatz et al.,1997; Weiss, 1998), which then impacts the relationship-specific performance of both buyer and supplier (Klein and Rai, 2009). Furthermore, when firms are unwilling to share sensitive information, they are not able to fully leverage the positive impact of information sharing on performance (Fawcett et al., 2007). This study explores the impact of sharing sensitive information. It is hypothesized, based on the findings of Thomas et al. (2011) that sharing sensitive information is associated with an increase in the time needed to resolve a problem. Since this information may contain details regarding the process or product specifications it also seems reasonable to expect that technology corrective actions will lead to an increase in the sharing of sensitive information. Hypotheses 6 propose:

H6a: Sharing sensitive information is positively associated with problem resolution time.

H6b: Sharing sensitive information is positively associated with technology corrective actions.

The conceptual model in Figure 1 illustrates the relationship of different relationship mechanisms on problem resolution time and type of corrective action. 
[Insert Figure 1]

\section{Method}

\subsection{Sample and Data Collection}

This analysis uses data from a complaints/problems database from a tier-one manufacturing supplier in the automotive industry. The data captures actual behaviors between buyer and supplier through the buyer's documentation of what took place for all documented complaints.

To the best of our knowledge this is the first paper to analyze such data. The data notes the use of multiple mechanisms used to resolve problems. Data was collected during and after the problem was resolved. The benefit of this observed data, as opposed to survey, is that it eliminates the opportunity for responder bias. Between 2010 and 2016 the buyer experienced 155 quality or delivery issues attributable to 24 suppliers. Most of the suppliers (13 out of 24 ) do a small part of their business with the buyer. Only six of the suppliers rely significantly on the buyer for business and the other five are moderately dependent on the buyer. Of the 24 suppliers, nine are large firms that employ over 2000. The rest of the suppliers are split evenly between small firms (8) employing fewer than 500 and mid-size firms (7) with 500 to 2000 employees. The market for the buyer's product is mature; therefore, most of the suppliers (18) operate within stable market conditions with relatively few changes to the product or process technology. Suppliers provided up to 22 unique part numbers, with the average being 6.3. The buyer single-sources product from its suppliers, therefore, product characteristics are dependent on the supplier, making it important to account for the supplier. The supplier demographics are provided by the purchasing manager who has over 40 years of experience with the firm.

The buyer has an established process to document supplier problems. If the supplier problem is deemed to have a significant impact on production and/or quality the buyer issues a 
complaint. Complaints are issued at the discretion of the buyer. These complaints are entered into a database and the supplier is required to input information. Suppliers document actions taken to communicate the problem, provide an explanation as to why the problem occurred, explain the corrective action implemented, and provide evidence that the corrective action was effective. The buyer reviews the information and may offer feedback, request additional information, or approve the actions taken by the supplier. The buyer and supplier may communicate multiple times. When the buyer is satisfied that the problem has been resolved, the buyer will close the complaint.

For this study, each complaint is reviewed for evidence of specific communication activities that occurred while resolving the problem. Only complaints that have been resolved and closed are included in the analysis. There is a separate file for each complaint. Within each file, multiple fields prompt the supplier to document the stages of the problem-solving process. These communication mechanisms are not only recommended in the buyer's problem resolution procedure but are also supported in the literature. However, it is the supplier's discretion as to how they will communicate and share information. The data collection process focused on keywords, words such as "team", "employee", or "onsite visit". The observed measures are based on the discussion of collaborative communication in the supply chain management literature. See Table 1 for a summary of the variables. The variables are either dichotomous or quantitative. The dichotomous variables are simply yes or no as to whether the mechanism of communicating was used.

[Insert Table 1] 


\subsection{Data Analysis}

For a given supplier, actions taken to resolve problems tend to be more like each other than across all suppliers. This study utilizes data collected from one buyer with multiple suppliers. The data includes different methods of communicating and sharing information both within and between firms. The methods used can vary depending on the supplier. Hence, the data is best analyzed as a multi-level problem given that complaints are nested within suppliers and the firm single sources incoming components (Klein et al., 1994). HLM examines both lower-level and higher-level variance, while maintaining the proper level of analysis for independent variables (Lee, 2003). Our study examines the dataset at the complaint level (lower level) and then the supplier level (higher level). The problem becomes one of independence of observations (Osborne, 2000). Ordinary least squares regression assumes independent observations and produces standard errors that are too small, leading to a higher probability of rejection. Greater attention to the levels within the data strengthens this analysis and resulting findings (Nezlek and Zyzniewski, 1998).

Two separate HLM models were run using SAS version 9.4. The SAS Mixed procedure is used for the dependent variable problem resolution time, while controlling for severity of the complaint and type of corrective action implemented. The SAS GLIMMIX procedure is used for the analysis of type of corrective action (a dichotomous variable) with a Newton-Raphson ridging optimization technique while controlling for the severity of the complaint. The convergence criteria (PCONV < 0.001) is satisfied for both models. The data merely notes if a mechanism is used by the buyer or supplier. The measures used are not created scales, therefore, there are no validity tests to report. 
Both HLM models control for severity of the complaint. Suppliers may be motivated to resolve some complaints more quickly than others. Two complaint factors address severity, major and repeat. Major complaints are those that create unusually high scrap or rework cost, causing significant downtime or external failures. Upper management determines when a complaint warrants being classified as a major. The second factor is whether there was a previous occurrence, designated as a repeat. These two factors may create a sense of urgency at the supplier, thereby influencing the time to resolve a problem or the corrective action.

Complaints labeled as major or repeat may require the supplier to participate in weekly or daily meetings and submit frequent progress updates. This equates to putting the supplier under a microscope where actions are more closely scrutinized, and suppliers are under pressure to resolve the problem quickly.

The analysis of problem resolution time also controls for the type of corrective action implemented. Type of corrective action implemented is important to consider because product or process redesign may extend the time to resolve the problem. The buyer requires any product changes to be thoroughly reviewed and verified. Moreover, changes in the process may require purchase of new equipment or tooling or equipment redesign.

\section{Results}

The results of the HLM analyses for both time and corrective action are summarized in Table 2. Significant results are in the bold-face font. A positive coefficient indicates that the variable is positively associated with time or associated with a technology corrective action. The analysis reveals problem resolution time is significantly different between suppliers, indicating some suppliers take longer to resolve issues.

[Insert Table 2] 


\subsection{Control Variables}

The severity of the complaint, measured by the variables major and repeat, has no influence on problem resolution time. However, repeat complaints are more likely to result in a technology corrective action. It suggests the supplier is encouraged to explore technology changes as opposed to changes in operator practices, given that technology changes may be considered a "better" fix to the problem (Agrawal and Muthulingam, 2015). This may be due to increased pressure by the buyer to implement irreversible corrective action. Possibly the pressure of time for the prior complaint led to a "quick fix", resulting in a reoccurrence of the problem. There are $7.1 \%$ major complaints and $14.2 \%$ repeat complaints. As suspected, a technology corrective action increases the time to closure $(\beta=3.76)$. Approximately two out of three corrective actions involve a change in technology. On average, when there is a change to an operator procedure, the time to resolve and close out the complaint takes 63.1 days. Technology changes take longer, on average, 116.8 days.

\subsection{Relationship mechanisms}

The most significant finding is the positive impact of dense communication on speed to closure $(\beta=-7.62)$. Dense communication considers how often the buyer and supplier communicate for a given period. As communication density increases, the buyer and supplier are frequently sharing information. The density of communication averages 0.08 with a maximum value of 0.32. This dense, i.e. frequent, communication allows both buyer and supplier to clarify the problem, discuss corrective action and review the supplier's progress. It can be argued that dense communication shortens the decision-making process. This study provides further support for the literature as to the positive influence of frequent communication on supply chain performance (MacDuffie, 1997; Large, 2005; Paulraj et al., 2008). Therefore, hypothesis 1a is supported. 
Dense communication is not associated with the type of corrective action implemented, therefore hypothesis $1 \mathrm{~b}$ is not supported.

In an employee meeting, management communicates face-to-face with employees about the problem, where employees are defined as the operators that produce the product. Employee meetings occurred in $42.6 \%$ of complaints. The literature provides evidence that face-to-face communication involving employees are beneficial (Wagner and Krause, 2009). These findings reveal that neither time nor type of corrective action are impacted when employee meetings are held. These results do not suggest that employee meetings have no benefit, merely that they do not impact the time or effectiveness of the problem-solving process. Thus, there is no support for hypotheses $2 \mathrm{a}$ and $2 \mathrm{~b}$.

According to Carr and Kaynak (2007), face-to-face communications improve supply chain performance. While on-site visits may be deemed a positive action, it is important to understand their impact on time. Only $11 \%$ of the complaints resulted in an onsite visit. The analysis reveals that conducting onsite visits increases problem resolution time, on average 71.8 days (161.8 - 90.2), supporting hypothesis 3a (Figure 2). Although onsite visits may be effective and enhance the buyer-supplier relationship, there is a negative impact on how quickly a problem is resolved. This result suggests that scheduling onsite visits requires additional time to coordinate. Another possibility is that suppliers might conduct an onsite visit for further clarification of the problem or possibly there is a need to review processes and the impact of potential corrective actions. These are all good reasons to conduct an onsite visit and extend the resolution time. Surprisingly these visits have no impact on the type of corrective action implemented. Therefore, hypothesis $3 \mathrm{~b}$ is not supported.

[Insert Figure 2] 
Establishing a management team early in the process is more likely to lead to a change in technology, providing support for hypothesis $4 \mathrm{~b}$. Part of the initial phase in problem resolution is to determine root cause and finalize corrective action (Sims, 2011). In the database, under the field "Immediate action taken" the supplier notes whether a management team is established. These findings suggest when teams are part of the process, the expertise and knowledge of the team leads to a process or product change. Cooperation is more likely when employees are involved in determining root cause and corrective action (Habtoor, 2016). Additionally, the findings reveal that problem resolution time is not impacted when management teams are established. Thus, there is no support for hypothesis 4a. For most of the complaints (123), no management teams were established. But, for the 32 complaints (20.6\%) that did establish a management team, $84.3 \%$ of the time the corrective action resulted in a change in technology compared to $60.1 \%$ when no team is established (Figure 3).

[Insert Figure 3]

The number of documents shared is used as a dimension of information sharing, another means of communicating. The results show the longer a complaint is open the more documents are shared $(\beta=2.85)$. The average number of documents shared is 7.8 , with a maximum of 40 . This might suggest that the buyer is not convinced that the corrective action is effective and requires the supplier to provide additional supporting documentation. The findings might also suggest that the increase is because additional documentation requires more time to process. Therefore, hypothesis $5 \mathrm{a}$ is accepted. However, an increase in information sharing is not associated with technology changes, thus hypothesis $5 \mathrm{~b}$ is not supported.

Some documents, such as process or product prints and failure mode analysis contain sensitive information and are considered proprietary documents. A supplier may be reluctant to 
share this information, yet sharing sensitive information occurs $47.1 \%$ of the time. Possibly this is due to the fact the buyer single sources product and there is an increased level of trust due to lack of competition. Sharing sensitive information has no impact on time and therefore hypothesis $6 \mathrm{a}$ is not supported. This result implies that the increase in information sharing discussed in hypothesis $5 \mathrm{a}$ is linked to documentation supporting the effectiveness of the corrective action rather than proprietary information. As expected, when the corrective action involves a change in technology there is an increase in sharing of sensitive documents. Thus, hypothesis $6 \mathrm{~b}$ is supported. Most likely there is significantly more sharing of sensitive information for technology changes since these changes may require an update to process or product prints. Sensitive documents are shared for $70.0 \%$ of technology changes as compared to 26.4\% for operator changes. The question for the buyer is whether to require sensitive information be shared whenever a product or process is changed. There may be an inconsistency in the requirement to share proprietary information since it did not occur for all technology corrective actions.

\section{Discussion}

Organizations deal with supplier problems on an on-going basis which can impact a firm's profitability and reputation. Problem resolution is important, occurring across all organizations and requires a collaborative effort. The relational view talks about relational linkages that provide value. One means of creating value is to share information and collaborate with suppliers to resolve problems. There are two ways to look at problem resolution. Firms want problems resolved quickly, but also correctly. This presents a challenge for both suppliers and buyers. In this study, the impact of collaborative mechanisms on these two problem resolution measures is explored. How firms collaborate is important because different mechanisms have different 
effects. What this study finds is the observed mechanisms affect either speed of problem resolution or effectiveness, but not both.

There is a gap in the literature for supplier problem resolution. Collaborative knowledge sharing routines have been discussed, but the complexity of these routines is not fully understood. Managers who deal with supply issues need to pay attention to these results given that how firms communication and share information impacts the speed and effectiveness at which problems are resolved. Supplier problem resolution by its nature is inter-organizational and dyadic and it is important to manage these relationships.

The literature points to the positive value of communication on supply chain performance (Krause et al., 1998; Carr and Kaynak, 2007; Paulraj et al., 2008; Gligor and Holcomb, 2012). But not all communication mechanisms have the same impact. Mechanisms work differently, and it matters that organizations pay attention to this. Frequent communication will result in a quicker resolution to a problem but sharing too much information lengthens the time. Previous studies discuss these mechanisms in a positive manner, but how they benefit the problem resolution process is different. These findings add to the literature on supply chain communication (Large, 2005; Modi and Mabert, 2007). Hence, the word to purchasing managers is to talk often to your suppliers.

Conducting onsite visits and sharing documents will extend the time to resolve a complaint. But there is a trade-off in that these mechanisms encourage and build relational rents between buyer and supplier (Dyer and Nobeoka, 2000; Li et al., 2012). With respect to onsite visits, possibly these visits are needed to provide further clarification of the problem or to understand the consequence of a corrective action. Managers may consider exploring new technologies for remote real-time communication or technologies that allow suppliers to develop 
and test the validity of their solution more quickly and in a more realistic manner. Sharing documents is one means of sharing information, however as the number of documents shared increases the time to closure increases. Sharing sensitive information, on the other hand is not associated with an increase in time. Managers should consider which documents are critical and how best to process the information.

The findings suggest that there is a trade-off between the speed at which a problem is resolved and the effectiveness of the solution. Changes in technology take longer but can prevent a reoccurrence of the problem. Repeat complaints are associated with a technology change which might imply the initial solution was reversible or incorrect. Technology changes are less reversible and considered a better "fix" to the problem (Agrawal and Muthulingam, 2015; Narayanan et al., 2009). Samsung provides a notable example of poor problem resolution due to pressure to quickly resolve a supply issue (Lopez, 2017). Extending the time to resolve a complaint is not necessarily a drawback in that poor managers demand quick fixes to problems (Antony, 2015). Therefore, the buyer must be wary of pressing too hard for a quick resolution.

Given that a technology solution is often more desirable, management teams are an effective practice in that these teams are more likely to implement a technology corrective action. The results suggest that the expertise of the team leads to a more effective solution and provide value with their diverse perspectives and multiple viewpoints (Salaheldin, 2009; Schmidt, 2012; Harvey, 2014). The cooperative nature of teams allows for increased employee involvement which increases the probability of a successful solution and implementation.

The key premise of this paper is that relational rents can be gained through value-adding mechanisms that are collaborative and enable inter-firm communication and information sharing. These mechanisms are important for inter-organizational problem resolution. The results extend 
the literature on the relational view in the context of supply chain management (Dyer and Singh, 1998; Chen \& Paulraj, 2004). The findings reveal that different practices have varying impact on the time to resolve a problem and influence the type of corrective action a supplier implements.

\section{Limitations and future research}

Future research linking repeat complaints to prior occurrences would provide additional insights as to why the problem resurfaced. What didn't the supplier do effectively when resolving the prior occurrence? This requires a conscious effort to track and link complaints over time. Additionally, these findings are relevant for one automotive manufacturing supplier and its supply chain. The results may not apply to other firms or industries. Therefore, obtaining information as to how other firms and industries communicate and resolve their supply issues are needed to confirm these results.

One of the limitations of this research is that the data entered into the database was done without prior knowledge that it was to be used for this study. Therefore, input from suppliers may not be consistent across complaints and it may not reflect all activity that occurred. It cannot be assumed that all communication was documented in the database.

There is a vast amount of literature that discusses the relationship between communication and strategic firm performance, but few studies examine relationship building mechanisms and how each varies in its impact on problem resolution. It is significant to understand that the speed at which problems are corrected and how they are resolved may depend on the relationship mechanisms employed by the buyer and supplier, both internally and between firms. Managers can benefit from these new insights. 


\section{References}

Agrawal, A. and Muthulingam, S. (2015), Does organizational forgetting affect vendor quality performance? An empirical investigation, Manufacturing \& Service Operations Management, Vol. 17 No. 3, pp. 350-367.

Antony, J. (2015), The ten commandments of quality: A performance perspective, International Journal of Productivity and Performance Management, Vol. 64 No. 5, pp. 723-735.

Argote, L. (2012), The Oxford Handbook of Organizational Psychology, Oxford University Press, New York, NY.

Bajaj, S., Garg, R. and Sethi, M. (2018), Total quality management: A critical literature review using Pareto analysis, International Journal of Productivity and Performance Management, Vol. 67 No. 1, pp. 128-154.

Bello, D. and Bovell, L. (2012), Collaboration analysis: Joint resolution of problems in global supply networks, Information Knowledge Systems Management, Vol.11 No. 1/2, pp. 77 99.

Bourgeois, L.J. III and Eisenhardt, K.M. (1988), Strategic decision processes in high velocity environments: Four cases in the microcomputer industry, Management Science, Vol. 34 No. 7, pp. 816-835.

Brown, J.S. and Duguid, P. (1991), Organizational learning and communities-of-practice: Toward a unified view of working, learning, and innovation, Organization science, Vol. 2 No. 1, pp. 40-57. 
Carr, A.S. and Kaynak, H. (2007), Communication methods, information sharing, supplier development and performance: An empirical study of their relationships, International Journal of Operations \& Production Management, Vol. 27 No. 4, pp. 346-370.

Charterina, J. and Landeta, J. (2013), Effects of knowledge-sharing routines and dyad-based investments on company innovation and performance: An empirical study of Spanish manufacturing companies, International journal of Management, Vol. 30 No.1, pp. 2039.

Chen, I.J. and Paulraj, A. (2004), Towards a theory of supply chain management: The constructs and measurements, Journal of operations management, Vol. 22 No. 2, pp. 119-150.

Cheng, J. and Jeong, E.Y. (2016), Galaxy Note 7 recall sinks Samsung profit; net profit declines $16.8 \%$ as overall operating profit falls $30 \%$, available at: https://www.wsj.com/articles/samsung-profit-falls-on-galaxy-note-7-recall-1477526701/ (accessed 02 February 2019).

Deming, W.E. (1986), Out of the Crisis, Cambridge University Press, Cambridge, UK.

Dyer, J.H. and Singh, H. (1998), The relational view: Cooperative strategy and sources of interorganizational competitive advantage, Academy of management review, Vol. 23 No. 4, pp. 660-679.

Dyer, J. and Nobeoka, K. (2000), Creating and managing a high-performance knowledge sharing network: The Toyota case, Strategic Management Journal, Vol. 21 No. 3, pp. 345-367. 
Fawcett, S.E., Osterhaus, P., Magnan, G.M., Brau, J.C. and McCarter, M.W. (2007), Information sharing and supply chain performance: The role of connectivity and willingness, Supply Chain Management: An International Journal, Vol. 12 No. 5, pp. 358-368.

Foster Jr, S.T. (2008), Towards an understanding of supply chain quality management, Journal of Operations Management, Vol. 26 No. 4, pp. 461-467.

Gligor, D.M. and Holcomb, M.C. (2012), Antecedents and consequences of supply chain agility: Establishing the link to firm performance, Journal of Business Logistics, Vol. 33 No. 4, pp. 295-308.

Habtoor, N. (2016), Influence of human factors on organisational performance: Quality improvement practices as a mediator variable, International Journal of Productivity and Performance Management, Vol. 65 No. 4, pp. 460-484.

Harvey, S. (2014), Creative synthesis: Exploring the process of extraordinary group creativity, Academy of Management Review, Vol. 39 No. 3, pp. 324-343.

Jagoda, K., Lonseth, R. and Lonseth, A. (2013), A bottom-up approach for productivity measurement and improvement. International Journal of Productivity and Performance Management, Vol. 62 No.4, pp. 387-406.

Klein, K.J., Dansereau, F. and Hall, R.J. (1994), Levels issues in theory development, data collection, and analysis, Academy of Management review, Vol. 19 No. 2, pp. 195-229.

Klein, R. and Rai, A. (2009), Interfirm strategic information flows in logistics supply chain relationships, MIS Quarterly, Vol. 33 No. 4, pp. 735-762. 
Ko, D.G., Kirsch, L.J. and King, W.R. (2005), Antecedents of knowledge transfer from consultants to clients in enterprise system implementations, MIS quarterly, Vol. 29 No.1, pp. 59-85.

Krause, D. R., Handfield, R. B. and Scannell, T.V. (1998), An empirical investigation of supplier development: Reactive and strategic processes, Journal of Operations Management, Vol. 17 No. 1, pp. 39-58.

Kuei, C.H., Madu, C.N. and Lin, C. (2008), Implementing supply chain quality management. Total Quality Management, Vol. 19 No. 11, pp. 1127-1141.

Large, R.O. (2005), External communication behaviour of purchasers - effects on supplier management performance, Journal of Purchasing and Supply Management, Vol. 11 No. 1, pp. 28-41.

Lascelles, D. M. and Dale, B. G. (1989), The buyer-supplier relationship in total quality management", Journal of Purchasing and Materials Management, Vol. 25 No. 2, pp. 1019.

Lee, B.H. (2003), Using hierarchical linear modeling to illustrate industry and group effects on organizational commitment in a sales context, Journal of Managerial Issues, Vol. 15 No. 3, pp. 353-368.

Li, Y., Tarafdar, M. and Subba Rao, S. (2012), Collaborative knowledge management practices: theoretical development and empirical analysis, International Journal of Operations \& Production Management, Vol. 32 No 4, pp. 398-422. 
Liker, J. K. and Choi, T. Y., (2004), Building deep supplier relationships, Harvard business review, Vol. 82 No. 12, pp. 104-113.

Lopez, M. (2017), Samsung explains Note7 battery explosions, and turns crisis into opportunity, available at: https://www.forbes.com/sites/maribellopez/2017/01/22/samsung-revealscause-of-note-7-issue-turns-crisis-into-opportunity/\#c559bb824f12/ (accessed 02 February 2019).

MacDuffie, J. P. (1997), The road to "root cause": Shop-floor problem-solving at three auto assembly plants, Management Science, Vol. 43 No. 4, pp. 479-502.

McLain, S. (2016), Toyota recalls 5.8 million vehicles with faulty Takata air bags; the faulty air bags lack a drying agent, making them prone to exploding, available at: https://www.wsj.com/articles/toyota-recalls-5-8-million-vehicles-with-faulty-takata-airbags-1477463338/ (accessed 12 December 2018).

Modi, S.B. and Mabert, V.A., (2007), Supplier development: Improving supplier performance through knowledge transfer, Journal of operations management, Vol. 25 No. 1, pp. 4264.

Narayanan, S., Balasubramanian, S. and Swaminathan, J. M. (2009), A matter of balance: Specialization, task variety, and individual learning in a software maintenance environment, Management Science, Vol. 55 No. 11, pp. 1861-1876.

Nezlek, J.B. and Zyzniewski, L.E. (1998), Using hierarchical linear modeling to analyze grouped data, Group Dynamics: Theory, Research, and Practice, Vol. 2 No. 4, pp. 313-320. 
Osborne, J.W. (2000), The advantages of hierarchical linear modeling, Practical Assessment, Research \& Evaluation, Vol. 7 No. 1. https://pareonline.net/getvn.asp?v=7\&n=1 (accessed March 1, 2019).

Oxford College of Procurement and Supply (2019), Why communication is key to supply chain success, available at: https://www.oxfordcollegeofprocurementandsupply.com/whycommunication-is-key-to-supply-chain-success (accessed 20 February 2019).

Park, S., Kim, Y.S. and Chan, P. (2006), Impact of quality management practices on suppliers' quality performance: Empirical evidence from Korean automotive parts suppliers. The Asian Journal on Quality, Vol. 7 No. 1, pp. 206-222.

Paulraj, A., Lado, A. A. and Chen, I. J. (2008), Inter-organizational communication as a relational competency: Antecedents and performance outcomes in collaborative buyersupplier relationships, Journal of Operations Management, Vol. 26 No. 1, pp. 45-64.

Phan, A.C., Abdallah, A.B. and Matsui, Y. (2011), Quality management practices and competitive performance: Empirical evidence from Japanese manufacturing companies, International Journal of Production Economics, Vol. 133 No. 2, pp. 518-529.

Pooe, D., Mafini, C. and Loury-Okoumba, V. W. (2015), The influence of information sharing, supplier trust and supplier synergy on supplier performance: The case of small and medium enterprises, Journal of Transport and Supply Chain Management, Vol. 9 No. 1, pp. 1-11.

Ragatz, G. L., Handfield, R. B. and Scannell, T.V. (1997), Success factors for integrating suppliers into new product development", Journal of Production and Innovative Management, Vol. 14 No. 3, pp. 190-202. 
Robinson, C.J. and Malhotra, M.K. (2005), Defining the concept of supply chain quality management and its relevance to academic and industrial practice, International Journal of Production Economics, Vol. 96 No. 3, pp. 315-337.

Salaheldin, S. I. (2009), Critical success factors for TQM implementation and their impact on performance of SMEs. International journal of productivity and performance management, Vol. 58 No. 3, pp. 215-237.

Salvador, F., Forza, C., Rungtusanatham, M. and Choi, T.Y. (2001), Supply chain interactions and time-related performances: An operations management perspective. International Journal of Operations \& Production Management, Vol. 21 No. 4, pp. 461-475.

Schmidt, M. (2012), General Motors Technical Problem-Solving Group Drives Excellence, case study, viewed 14 February 2019, https://secure.asq.org/perl/msg.pl?prvurl=http://asq.org/2012/11/problemsolving/general-motors.pdf

Sims, D. (2011), Seven simple rules for solving problems, Industrial Engineer, Vol. 43 No. 3, pp. 37-40.

Soares, A., Soltani, E. and Liao, Y.Y. (2017), The influence of supply chain quality management practices on quality performance: An empirical investigation, Supply Chain Management: An International Journal, Vol. 22 No. 2, pp. 122-144.

Swink, M. (2006), Building collaborative innovation capability. Research-technology management, Vol 49 No. 2, pp. 37-47. 
Thomas, R. W., Fugate, B. S. and Koukova, N. T. (2011), Coping with time pressure and knowledge sharing in buyer-supplier relationships, Journal of Supply Chain Management, Vol. 47 No. 3, pp. 22-42.

Wagner, S. M. and Krause, D. R. (2009), Supplier development: Communication approaches, activities and goals, International Journal of Production Research, Vol. 47 No. 12, pp. 3161-3177.

Weiss, M. S. (1998), How to ensure supplier quality from your supplier management program, Hospital Material Management Quarterly, Vol. 19 No. 3, pp. 1-10.

Wood, C.H., Kaufman, A. and Merenda, J. (1996), How Hadco became a problem-solving supplier, Sloan Management Review, Vol. 37 No. 2, Winter, pp. 77-88.

Zander, U. and Kogut, B. (1995), Knowledge and the speed of the transfer and imitation of organizational capabilities: An empirical test, Organization Science, Vol. 6 No. 1, pp. 7692.

Zhang, L., Wang, S., Li, F., Wang, H., Wang, L. and Tan, W. (2011), A few measures for ensuring supply chain quality, International Journal of Production Research, Vol. 49 No. 1, pp. 87-97. 